\title{
Surgical ablation for atrial fibrillation: The efficacy of a novel bipolar pen device in the cardioplegically arrested and beating heart
}

\author{
Shun-ichiro Sakamoto, MD, Rochus K. Voeller, MD, Spencer J. Melby, MD, Shelly C. Lall, MD, Nai-lun Chang, BA, \\ Richard B. Schuessler, PhD, and Ralph J. Damiano, Jr, MD
}

\begin{abstract}
Objective: The introduction of ablation technology has simplified surgical intervention for atrial fibrillation. However, most ablation devices cannot create focal transmural lesions on the beating heart and have difficulty ablating specific regions of the atria, such as the atrioventricular isthmus, coronary sinus, and ganglionated plexus. The purpose of this study was to examine the efficacy of a pen-type bipolar radiofrequency ablation device on both arrested and beating hearts.
\end{abstract}

\begin{abstract}
Methods: Endocardial and epicardial atrial tissues in the free wall, left atrial roof, atrioventricular annuli, and coronary sinus were ablated for varying time intervals (2.5-15 seconds) in porcine cardioplegically arrested $(n=6)$ and beating $(n=9)$ hearts. The hearts were stained with $1 \% 2,3,5$-triphenyl-tetrazolium chloride solution and sectioned to determine lesion depth and width. In 5 animals epicardial fat pads containing ganglionated plexus were stimulated and ablated.
\end{abstract}

Results: Lesion depth increased with ablation time similarly in both arrested and beating hearts. Transmurality was fully achieved in the thin atrial tissue $(<4 \mathrm{~mm})$ at 10 seconds in the beating and arrested hearts. The device had a maximal penetration depth of $6.1 \mathrm{~mm}$. Epicardial ablation of the coronary sinus showed complete penetration through the left posterior atrium only in the arrested heart. Seven of 17 fat pads demonstrated a vagal response. All vagal responses were eliminated after ablation.

Conclusion: The bipolar pen effectively ablated atrial tissue in both arrested and beating hearts. This device might allow the surgeon to ablate tissue in regions not accessible to other devices during atrial fibrillation surgery.

The introduction of alternative energy sources for creating atrial lesions has made atrial fibrillation $(\mathrm{AF})$ surgery more accessible to surgeons by reducing the difficulty and length of these procedures. ${ }^{1-4}$ One of these new technologies, bipolar radiofrequency $(\mathrm{RF})$ ablation, has been shown by our laboratory and others to reliably create continuous transmural linear lesions on both the arrested and the beating heart. ${ }^{5-7}$ These devices require the surgeon to clamp the atrial tissue between 2 jaws with embedded electrodes. These devices, although effective, have significant shortcomings.

First of all, they are unable to ablate up to the tricuspid and mitral valve annuli because of the thickness of the atrioventricular groove. There are also concerns about ablating directly on the coronary arteries or valve tissue.

Second, it is not possible to create small focal lesions because of the length of the electrodes. As an example, recent data have suggested that there might be a benefit from focal

\footnotetext{
From the Division of Cardiothoracic Surgery, Washington University School of Medicine, Barnes-Jewish Hospital, St. Louis, Mo.

Supported in part by National Institutes of Health grants RO-1HL032257-21 and F32 HL082129-02; and a grant from AtriCure Inc, West Chester, OH. Richard Schuessler and Ralph Damiano report consulting fees and grant support from Atricure.

Received for publication Jan 24, 2008; revisions received March 18, 2008; accepted for publication April 3, 2008.

Address for reprints: Ralph J. Damiano, Jr, MD, Department of Cardiac Surgery, Washington University School of Medicine, Barnes-Jewish Hospital, 3108 Queeny Tower, One Barnes-Jewish Hospital Plaza, St. Louis, MO 63110 (E-mail: damianor@wustl.edu).

J Thorac Cardiovasc Surg 2008;136:1295-301

$0022-5223 / \$ 34.00$

Copyright (C) 2008 by The American Association for Thoracic Surgery

doi:10.1016/j.jtcvs.2008.04.030
}

ablation of fat pads or atrial tissue containing ganglionated plexi (GPs) and fibers thought to be responsible for the initiation of AF. ${ }^{8}$ Unfortunately, most of the presently available unipolar technology (ie, RF energy, microwave, and cryoablation) has been unable to reliably create transmural lesions on the beating heart. ${ }^{9-12}$ It would be necessary to develop a new device that can be used for epicardial ablation on the beating heart and for ablating tissue in regions not accessible to other devices during AF surgery to overcome these shortcomings. A novel bipolar pen (Isolator Transpolar Pen; AtriCure, Inc, West Chester, Ohio) was developed to create these ablations on both arrested and beating hearts.

The purpose of this study was to test the performance of a bipolar probe that can apply RF energy on both arrested and beating hearts. The ability of this device to create transmural lesions up to the mitral and tricuspid annuli, over the coronary sinus, and on the atrial free wall was evaluated in an acute porcine model. In addition, the GP fat pad was stimulated and ablated to test the efficacy of the pen device to ablate GPs.

\section{MATERIALS AND METHODS \\ Ablation Device}

Lesions were created with the Isolator Transpolar Pen (AtriCure, Inc; Figure 1). The device consists of a handheld probe with a 5-mm-wide tip, an integral cable passing through a flexible shaft, and a reusable ablation and sensing unit. Two 1-mm-wide, 8 -mm-long electrodes separated by 3 $\mathrm{mm}$ of insulation are located on the tip of the pen. RF energy is driven between the 2 electrodes. During energy delivery, the ablation and sensing unit adjusts energy delivery by determining online measurements of tissue 


\section{Abbreviations and Acronyms \\ $\mathrm{AF}=$ atrial fibrillation \\ $\mathrm{GP}=$ ganglionated plexus \\ $\mathrm{RF}=$ radiofrequency}

conductance every $20 \mathrm{~ms}$ during ablation. The power delivered varies depending on the measured conductance at each time point. Conductance was calculated from measurements of current and voltage. The pen operated at a maximum power setting of $15 \mathrm{~W}$, and to minimize tissue damage, such as charring and perforation, the power tapered down as tissue impedance increased beyond $400 \Omega$.

\section{Experimental Protocol}

Fifteen domestic pigs weighing 70 to $80 \mathrm{~kg}$ were used in this study. All animals received humane care in compliance with the "Guide for the care and use of laboratory animals" published by the National Institutes of Health (publication no. 85-23, revised). Each animal was premedicated with intramuscular ketamine, intubated, and anesthetized with $2 \%$ to $4 \%$ isoflurane. Heart rate, blood pressure, and oxygen saturation were monitored continuously throughout the procedure. The heart was exposed through a median sternotomy. In 6 animals (group A, arrested heart) a cardioplegia cannula was placed in the proximal ascending aorta. After systemic heparinization $(100 \mathrm{U} / \mathrm{kg})$, the superior vena cava and inferior vena cava were snared with umbilical tapes, and the aorta was crossclamped. A cardioplegic solution (Plegisol; Abbott Laboratories, North Chicago Ill) was infused at a volume of $10 \mathrm{mg} / \mathrm{kg}$ into the aortic root at a pressure of 70 to 80 $\mathrm{mm} \mathrm{Hg}$. A myocardial temperature probe was placed into the interventricular septum, and a normal saline slush solution was placed topically on the heart to maintain myocardial temperature between $10^{\circ} \mathrm{C}$ and $15^{\circ} \mathrm{C}$. Cardioplegia solution was infused every 20 minutes to maintain cardiac arrest. After the atriotomy, timed endocardial stamping lesions were created on the right and left atrial free walls for durations of 2.5, 5, 7.5, 10, 12.5, and 15 seconds and up to the posterior mitral annulus and the anterior tricuspid annulus for durations of 5, 10, and 15 seconds. Timed epicardial stamping lesions were created on the coronary sinus for ablation durations of 5,10 , and 15 seconds.

In 9 animals (group B, beating heart) epicardial stamping lesions were created on the right and left atrial free walls and coronary sinus on the beating normothermic heart without cardiopulmonary bypass. Timed atrial ablations were performed for durations of $2.5,5,7.5,10,12.5$, and 15

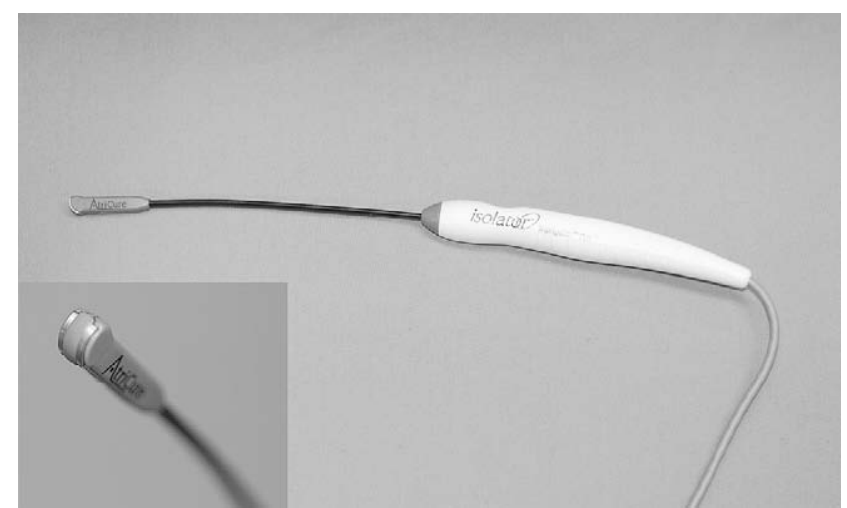

FIGURE 1. Isolator Transpolar Pen (AtriCure, Inc).

seconds on the atrial free wall, and coronary sinus ablations were performed for durations of 5, 10, and 15 seconds. Timed atrial ablations were performed for durations of $7.5,10,12.5$, and 15 seconds on the left atrial roof. The ablation times at each atrial site were randomized so as to avoid any confounding influence of changes in atrial wall thickness at each site. In 5 animals the tip of the pen device was placed on the 4 anatomic GP fat pads (interatrial septal, dorsal atrial, ventral right atrial, and left superior vena cava-left atrial fat pad) ${ }^{13}$ to deliver high-frequency stimulation at a rate of 1000 pulses/min with a pulse duration of 0.1 to $1.5 \mathrm{~ms}$ and voltage of approximately 1 to 6 V (PACE 203H; Oscar, Inc, Denver, Colo). During highfrequency stimulation, the electrocardiogram was monitored to detect R-R prolongation. R-R prolongation by $10 \%$ or atrioventricular block was defined as a positive vagal reflex caused by GP stimulation. GP fat pads were ablated for 5, 10, and 15 seconds, respectively, in each animal. High-frequency stimulation was repeated only on the GP fat pads that had demonstrated a vagal reflex before the ablation.

\section{Histologic Assessment}

At the end of the procedure, the animals were killed, and the hearts were removed en bloc. The atrial ablation lesions were examined for evidence of charring and tissue disruption. The heart was placed in a $1 \% 2,3,5$-triphenyl-tetrazolium chloride solution and incubated at room temperature for 45 minutes. Each lesion was sectioned at the midportion, perpendicular to the long axis of the ablation. Each section was photographed digitally next to a 5-mm caliper. Lesion width and depth and myocardial tissue thickness were analyzed with commercial software (Adobe Photoshop, San Jose,

TABLE 1. Atrial lesion sets in groups A and B

\begin{tabular}{|c|c|c|c|c|c|c|}
\hline \multirow[b]{2}{*}{ Ablation time (s) } & \multicolumn{2}{|c|}{ Ablation width (mm) } & \multicolumn{2}{|c|}{ Ablation depth (mm) } & \multicolumn{2}{|c|}{ Tissue thickness (mm) } \\
\hline & Group A & Group B & Group A & Group B & Group A & Group B \\
\hline 2.5 & $\begin{array}{l}2.5 \pm 0.9 \\
(1.2-3.7)\end{array}$ & $\begin{array}{l}4.3 \pm 2.3 \\
(0.5-10.2)\end{array}$ & $\begin{array}{l}1.1 \pm 0.7 \\
(0.5-2.2)\end{array}$ & $\begin{array}{l}1.6 \pm 1.0 \\
(0.2-5.0)\end{array}$ & $\begin{array}{l}2.9 \pm 1.4 \\
(1.2-4.7)\end{array}$ & $\begin{array}{c}3.4 \pm 2.0 \\
(0.7-5.4)\end{array}$ \\
\hline 5.0 & $\begin{array}{l}3.5 \pm 1.1 \\
(1.9-5.8)\end{array}$ & $\begin{array}{l}6.2 \pm 2.2 * \\
(2.9-10.7)\end{array}$ & $\begin{array}{l}2.2 \pm 0.9^{*} \\
(0.6-3.8)\end{array}$ & $\begin{array}{l}2.1 \pm 1.1 \\
(0.9-4.3)\end{array}$ & $\begin{array}{l}3.0 \pm 1.0 \\
(1.2-4.6)\end{array}$ & $\begin{array}{l}2.8 \pm 1.3 \\
(0.9-4.9)\end{array}$ \\
\hline 7.5 & $\begin{array}{c}4.1 \pm 1.5 \\
(2.0-7.5)\end{array}$ & $\begin{array}{c}7.0 \pm 2.4 \\
(4.1-13.2)\end{array}$ & $\begin{array}{l}2.6 \pm 1.1 \\
(0.9-4.4)\end{array}$ & $\begin{array}{l}2.3 \pm 0.9 * \\
(1.2-5.1)\end{array}$ & $\begin{array}{c}3.0 \pm 1.4 \\
(0.9-4.8)\end{array}$ & $\begin{array}{c}2.9 \pm 1.0 \\
(1.2-5.1)\end{array}$ \\
\hline 10.0 & $\begin{array}{l}4.9 \pm 1.3^{*} \\
(2.3-7.4)\end{array}$ & $\begin{array}{c}7.5 \pm 3.1 \\
(3.7-13.7)\end{array}$ & $\begin{array}{c}2.6 \pm 0.9 \\
(1.4-4.7)\end{array}$ & $\begin{array}{l}2.7 \pm 1.0 \\
(1.1-4.9)\end{array}$ & $\begin{array}{l}2.6 \pm 0.9 \\
(1.4-4.7)\end{array}$ & $\begin{array}{l}3.7 \pm 2.3 \\
(1.1-8.6)\end{array}$ \\
\hline 12.5 & $\begin{array}{c}4.9 \pm 1.4 \\
(2.2-7.0)\end{array}$ & $\begin{array}{l}7.4 \pm 2.7 \\
(2.7-14.0)\end{array}$ & $\begin{array}{c}2.2 \pm 0.8 \\
(0.8-3.3)\end{array}$ & $\begin{array}{l}3.0 \pm 1.1 \ddagger \\
(1.5-5.5)\end{array}$ & $\begin{array}{c}2.5 \pm 1.2 \\
(0.8-5.2)\end{array}$ & $\begin{array}{l}3.4 \pm 1.7 \\
(1.5-9.4)\end{array}$ \\
\hline 15.0 & $\begin{array}{l}5.7 \pm 1.4 \dagger \\
(2.6-7.7)\end{array}$ & $\begin{array}{l}7.6 \pm 2.6 \\
(3.8-13.2)\end{array}$ & $\begin{array}{c}3.1 \pm 0.9 \S \\
(1.3-5.3)\end{array}$ & $\begin{array}{l}3.1 \pm 1.4 \\
(1.1-6.1)\end{array}$ & $\begin{array}{l}3.1 \pm 0.9 \\
(1.3-5.3)\end{array}$ & $\begin{array}{l}3.1 \pm 1.4 \\
(1.1-6.1)\end{array}$ \\
\hline
\end{tabular}

Data are presented as mean values \pm standard deviation (range). Group $A$, Arrested heart; group $B$, beating heart. $* P<.05$ versus 2.5 -second lesion. $\dagger P<.05$ versus 5 -second lesion.

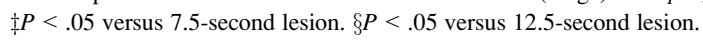




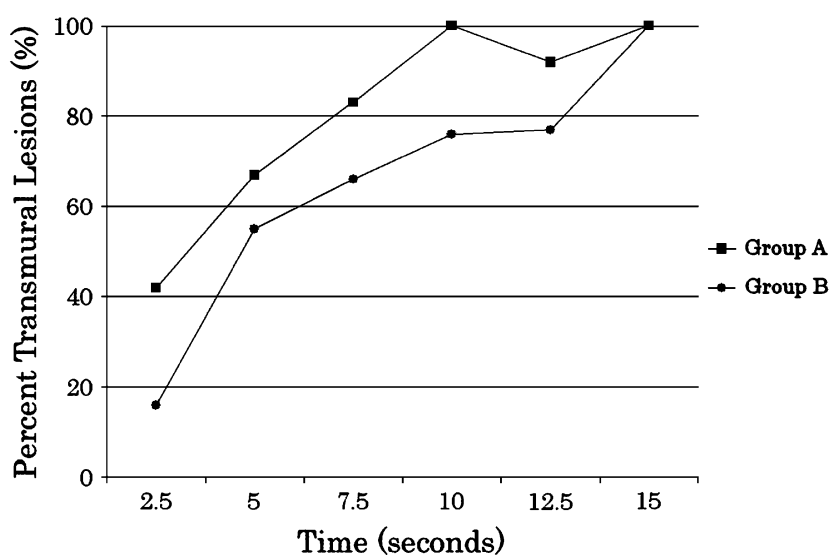

FIGURE 2. Percentage transmural lesions versus ablation time in the atrial lesions in groups A (arrested heart) and B (beating heart).

Calif), as described previously. ${ }^{11}$ Lesion depth and width were measured from the unstained area to the pink halo region surrounding each lesion. The accuracy of this technique was $\pm 0.03 \mathrm{~mm}$. Coronary sinus and epicardial fat pad lesions were sectioned and analyzed in the same manner as the atrial tissue. Each lesion was examined to determine the depth of penetration. Transmural lesions across the coronary sinus were defined as lesions that penetrated both the anterior and posterior walls that were adjacent to the left atrial tissue.

\section{Statistical Analysis}

Data were expressed as means \pm standard deviation. One-way analysis of variance was used to compare the lesion data in each ablation time. The quantitative difference between groups $\mathrm{A}$ and $\mathrm{B}$ was analyzed by means of 2-way analysis of variance. All statistical procedures were performed with the SPSS 11.5 statistical package (SPSS, Inc, Chicago, Ill).

\section{RESULTS}

On gross inspection, all lesions were pale and easily visible. Tissue disruption or charring was not observed in any lesion. On the arrested heart, there was no evidence of collateral damage with endocardial ablation with the pen device. Particularly, no lesion reached the parietal pericardium.
Atrial lesion depth was compared with atrial wall thickness in the area of ablation, and the number of transmural lesions was determined.

\section{Atrial Lesions}

In group A a total of 12 lesions were created for each ablation time on the endocardium of the right and left atrial free walls. In group B, on the beating heart, a total of $19 \pm 1.4$ lesions (range, 18-21 lesions) were created for each ablation time on the epicardium of the atrial free wall and the left atrial roof. The 2.5-second timed lesion had the smallest width and depth among any of the timed lesions in both groups (Table 1). Ablation depth increased in a time-dependent manner. Ablation width in each lesion was significantly greater in group B than in group A. On the other hand, there was no significant difference in ablation depth and tissue thickness between the 2 groups. The greatest lesion depths ( $5.3 \mathrm{~mm}$ in group A and $6.1 \mathrm{~mm}$ in group B) were observed after the 15 -second ablation.

Ablation times of more than 10 seconds achieved transmurality in all lesions in group A, except in one instance (12.5-second ablation), when the tissue thickness was 5.2 $\mathrm{mm}(35 / 36$ [97\%] ablations). In group B the percentage of transmurality was comparatively low at ablation times of more than 10 seconds (53/63 [84\%] ablations). Only a 15second ablation guaranteed a transmural lesion (Figure 2).

There were no transmural lesions when the tissue thickness was more than $6.7 \mathrm{~mm}$ (Figure 3). However, transmurality was fully achieved in thin atrial tissue $(\leq 4 \mathrm{~mm})$ at 10 seconds in both groups A and B.

\section{Mitral and Tricuspid Annulus Lesions on the Arrested Heart}

In group A a total of 12 lesions for each ablation time were created on the endocardium up to both the mitral and tricuspid annuli. The mean atrial tissue thickness was $2.2 \pm 1.1 \mathrm{~mm}$ (range, $0.8-4.0 \mathrm{~mm}$ ). Ablation width and depth in the
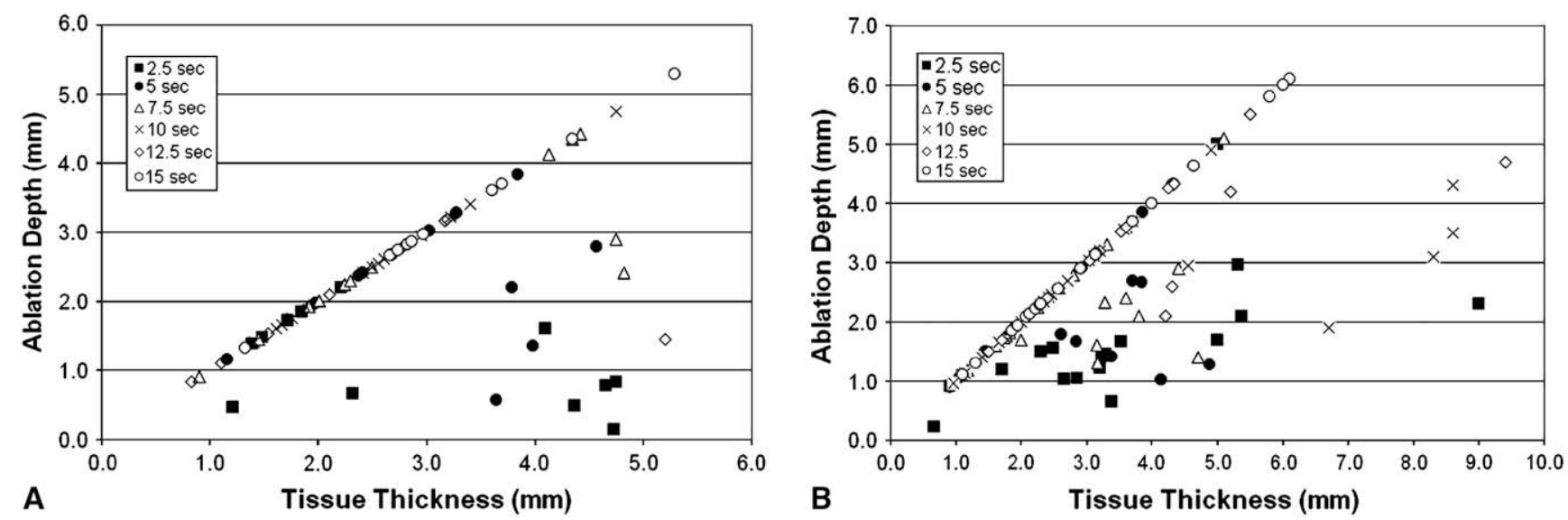

FIGURE 3. Relationship between ablation depth versus tissue thickness in groups A and B. 
TABLE 2. Endocardial lesion sets up to the mitral and tricuspid annuli

\begin{tabular}{lcccc}
\hline $\begin{array}{c}\text { Ablation } \\
\text { time (s) }\end{array}$ & $\begin{array}{c}\text { Ablation } \\
\text { width } \\
(\mathbf{m m})\end{array}$ & $\begin{array}{c}\text { Ablation } \\
\mathbf{d e p t h} \\
(\mathbf{m m})\end{array}$ & $\begin{array}{c}\text { Tissue } \\
\text { thickness } \\
(\mathbf{m m})\end{array}$ & $\begin{array}{c}\text { Transmurality } \\
\mathbf{( \% )}\end{array}$ \\
\hline 5.0 & $3.8 \pm 1.2$ & $1.6 \pm 0.3$ & $1.7 \pm 0.4$ & $83(10 / 12)$ \\
& $(2.1-5.3)$ & $(0.9-2.0)$ & $(1.3-2.9)$ & \\
10.0 & $5.9 \pm 1.0^{*}$ & $2.0 \pm 0.9$ & $2.0 \pm 0.9$ & $100(12 / 12)$ \\
& $(4.2-6.8)$ & $(0.8-3.6)$ & $(0.8-3.6)$ & \\
15.0 & $6.4 \pm 1.2$ & $2.3 \pm 0.7^{*}$ & $2.3 \pm 0.7^{*}$ & $100(12 / 12)$ \\
& $(4.7-8.5)$ & $(1.4-4.0)$ & $(1.4-4.0)$ & \\
\hline
\end{tabular}

$\overline{\text { Data are presented as mean values } \pm \text { standard deviation. } * P<.05 \text { versus } 5 \text {-second }}$ lesion.

5-second lesions were significantly less than those in the 15second lesions (Table 2). The percentage of transmural lesions up to the mitral and tricuspid annuli demonstrated that all lesions at ablation times of more than 10 seconds were transmural (24/24 ablations). There was no visible injury to the area surrounding the coronary arteries. Figure $4, A$, shows a 15 -second timed lesion up to the tricuspid annulus, which ablated the epicardial fatty tissue but did not reach the right coronary artery wall. With ablation up to the mitral annulus, the lesion reached the inferoposterior wall of the coronary sinus in 2 cases of 15 -second ablations (Figure 4, B).

\section{Coronary Sinus Lesions on the Arrested and Beating Hearts}

In both groups $50 \%$ of 5 -second ablations through the coronary sinus were not transmural. In contrast, lesions were transmural in all 10- and 15-second ablations. In group A lesions also penetrated down to the left atrium in $16 \%$ of 10 -second and $50 \%$ of 15 -second ablations (Figure 5).

\section{Epicardial GP Fat Pad Ablation}

Seventeen GP fat pads were visually identified in this study. Seven $(41 \%)$ fat pads (1 interatrial septal fat pad, 4 dorsal atrial fat pads, and 2 ventral fat pads) showed R-R prolongation during high-frequency stimulation (Figure 6, $A$ ). The vagal response was eliminated in all 7 fat pads after timed ablation. Lesions were created above all 17 fat pads, regardless of the vagal reflex. The pen could not penetrate the atrial tissue beneath the fat pad, except for one lesion in each of the 10- and 15-second ablations (Figure 6, B).

\section{DISCUSSION}

The introduction of ablation devices has revolutionized surgical intervention for AF. However, unipolar energy sources have not been capable of reliably creating transmural lesions on the beating heart. ${ }^{9-12}$ Epicardial fat, intramyocardial blood flow, and the presence of blood cooling the endocardial surface are assumed to be responsible for limiting the depth of penetration. Bipolar RF energy was devel-
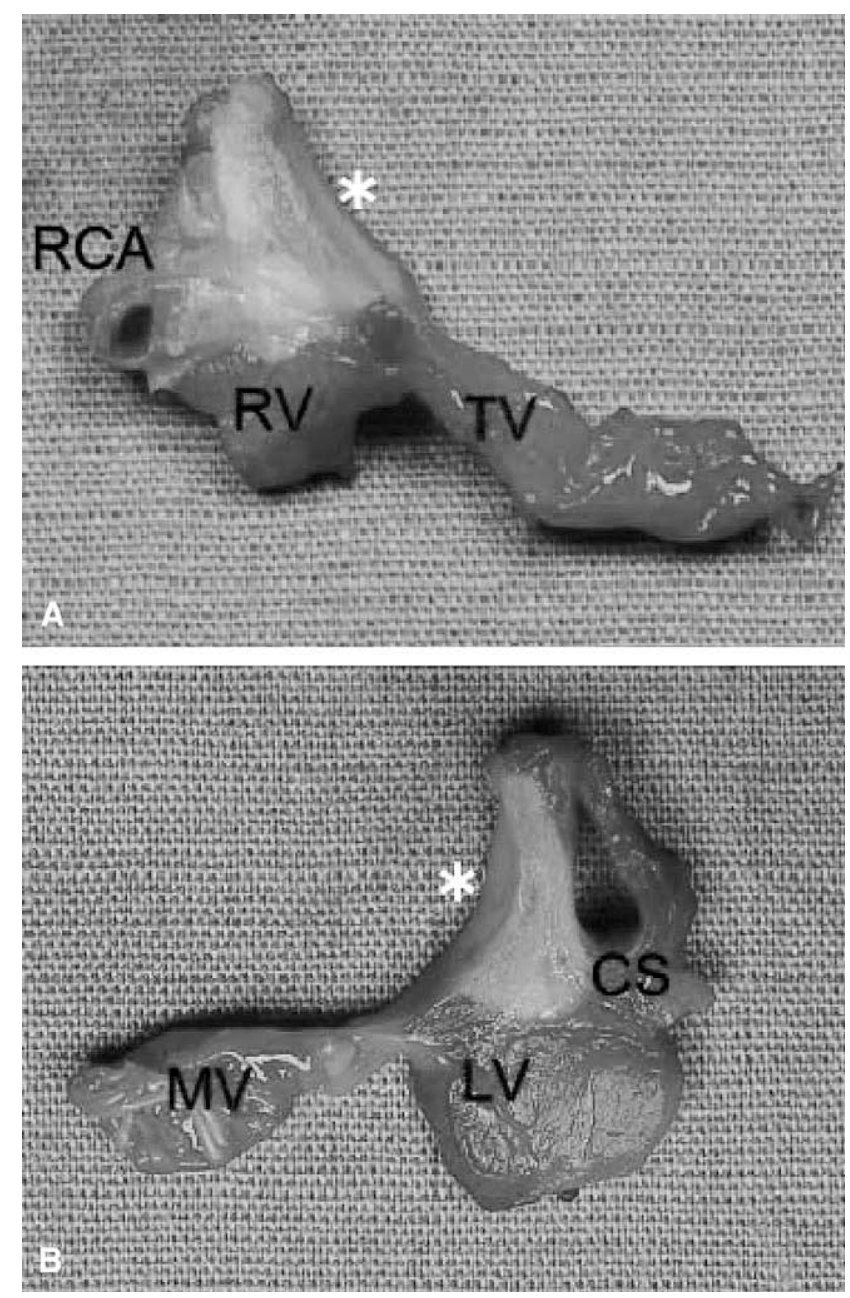

FIGURE 4. A, Example of a lesion near the tricuspid annulus. The asterisk indicates the ablation site on the endocardial surface. The ablation penetrates through the atrial tissue in the tricuspid annulus and reaches the epicardial fat tissue. B, Example of a lesion near the mitral annulus. The ablation penetrates through not only atrial tissue but also through the posterior wall of the coronary sinus. $R C A$, Right coronary artery; $R V$, right ventricle; $T V$, tricuspid valve; $C S$, coronary sinus; $L V$, left ventricle; $M V$, mitral valve.

oped to overcome this problem. These clamp devices have been shown to effectively create transmural lesions on both beating and arrested hearts. However, they have their own shortcomings and cannot ablate tissue near the tricuspid and mitral annuli or create spot lesions.

The Isolator Transpolar Pen is a handheld RF ablation device with a flexible shaft and a small tip. It has the potential advantage of a unique bipolar configuration and an energy output regulated by a tissue impedance algorithm. This controls energy delivery and limits charring at the tissue-electrode interface. It is recommended that the device be used, as in this study, with a stamping technique to maximize its effectiveness. If used correctly, it might be able to overcome the above-mentioned limitations of traditional devices. 

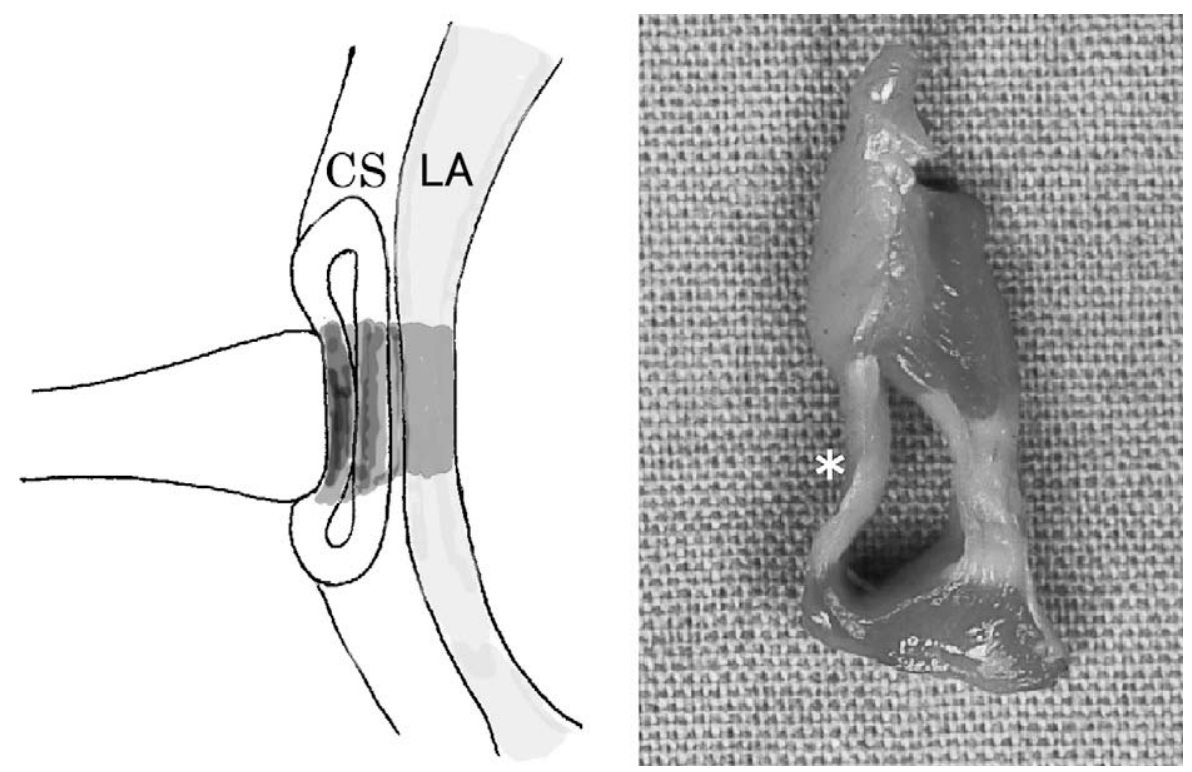

FIGURE 5. Transmural lesion across both the coronary sinus and left atrial tissue after a 15 -second ablation. The asterisk indicates the ablation surface of the coronary sinus. $C S$, Coronary sinus; $L A$, left atrium.

The most important finding of this study was that lesion depth and percentage of transmurality increased with ablation time in a similar fashion on both arrested and beating hearts. These similar dose-response relationships are different from those seen by our laboratory and others using unipolar RF and other microwave energy sources, which have significantly worse penetration on the beating heart when compared with that seen on the arrested heart. ${ }^{9-12}$

For this device, $80 \%$ of ablations on the arrested heart and $67 \%$ of ablations on the beating heart were transmural. The deepest penetration of the device was $6.1 \mathrm{~mm}$. For tissue thickness of $4 \mathrm{~mm}$ or less, all lesions were transmural at ablation times of 10 seconds and greater. For tissue thickness of $4 \mathrm{~mm}$ or greater, $50 \%$ of lesions at ablation times of 10 seconds or greater were transmural. According to previous anatomic studies, the thickness of the normal human atrium is different from site to site. ${ }^{14,15}$ Trabeculated areas and the crista terminalis in the right atrium show prominent wall thickness of greater than $6 \mathrm{~mm}$. In the left atrium the atrial roof between the right and left pulmonary veins is comparatively thicker than other parts of the left atrium. In the present study tissues in these regions were remarkably thick $(>8$ $\mathrm{mm}$ ) and were not transmurally ablated on the beating heart. Based on these data, epicardial ablation on the beating heart should be limited to the regions of atrial tissue with a thickness of $4 \mathrm{~mm}$ or less.

Another significant finding in the present study was that ablation width was wider on the beating heart when compared with that on the arrested heart. Lower myocardial temperature caused by topical cooling might have caused diminished lateral energy delivery on the arrested heart.

In the Cox maze III procedure, cryoablation was used to ablate the atrial tissue near the mitral and tricuspid annuli. ${ }^{16}$ Cryoablation is a reliable and safe technology that has been
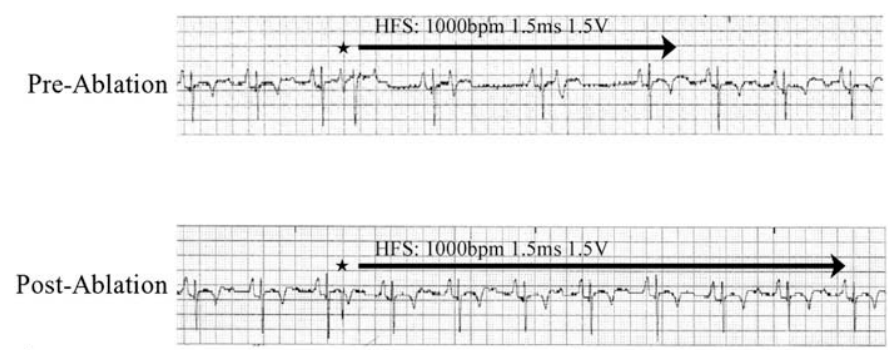

A

FIGURE 6. A, Electrocardiographic recording during high-frequency stimulation before and after ablation. Continuous high-frequency stimulation was applied to the ventral ganglion plexus fat pad and induced R-R slowing (upper panel). After a 10-second ablation, high-frequency stimulation at the same voltage failed to induce R-R slowing. Asterisks indicate the start of high-frequency stimulation. Arrows indicate its duration. B, The depth of penetration is shown in the upper cartoon. The asterisk indicates the epicardial surface. The ablation did not fully penetrate the underlying atrial myocardium. 
used for decades in the treatment of arrhythmias. However, creating transmural lesions takes 2 to 3 minutes. In our laboratory, although the bipolar RF clamp has been shown to create transmural lesions reliably and can replace most of the incisions of the Cox maze III procedure, ${ }^{17,18}$ it cannot ablate up to the mitral and tricuspid annuli because of the thickness of the atrioventricular groove tissue and the difficult dissection, particularly on the right atrium, required to avoid injury to the coronary arteries. Consequently, many surgeons have awaited the development of a new device capable of interrupting atrial isthmus tissue safely and rapidly. The Cardioblate pen (Medtronic, Minneapolis, Minn) is an irrigated unipolar $\mathrm{RF}$ ablation device that allows production of spot lesions and has been used for this purpose. ${ }^{19}$ It has a unipolar electrode and results in laterally oriented heating distribution. However, there are no experimental reports documenting time needed for ablation. A recent clinical study has shown that this device does not reliably create transmural lesions, particularly at the left atrial isthmus. ${ }^{20}$

On the other hand, the Isolator Transpolar Pen was particularly effective at creating lesions in the left and right atrial tissue near the valve annuli. This is an area of the atrium with relatively thin tissue, usually measuring 1 to $3 \mathrm{~mm}$ in human subjects. ${ }^{21,22}$ At both 10 - and 15-second ablation times, all lesions were transmural in this area.

Surgical ablation of the coronary sinus is an important part of surgical intervention for AF. The coronary sinus is covered with a continuous cuff of striated muscle extending from the right atrium, and there also are muscular connections with the left atrium. Therefore activation can conduct along the coronary sinus during $\mathrm{AF}^{23,24}$ Omission of the coronary sinus lesion has resulted in postoperative atrial flutter after a traditional Cox maze procedure in our experience. In the present study every 10 - and 15 -second ablation performed with the pen device created a transmural ablation of the coronary sinus. However, the pen could not penetrate left atrial tissue under the coronary sinus on the beating heart. Thus performing an epicardial ablation of the left atrial isthmus was possible only on the arrested heart.

Focal ablation of the GP has been proposed for the treatment of AF. Recent studies have shown that pulmonary vein isolation combined with GP ablation reduced the recurrence of $\mathrm{AF}^{25}$ In another study selective GP ablation was used to treat paroxysmal AF without pulmonary isolation. ${ }^{26}$ The epicardial GP contains efferent parasympathetic, sympathetic, and afferent neurons, but a vagal response is most often observed during GP stimulation. This increased vagal tone in the atrium can play an important role in initiating and maintaining $\mathrm{AF}^{27,28}$

In the present study the vagal reflex could be eliminated by ablation of the fat pad. Our data suggested that ablation of only the epicardial tissue was able to interrupt vagal GP. However, efferent vagal fibers are located not only epicardially but also intramyocardially or subendocardially. In a histologic study in the pig, the innervation patterns of epicardium and endocardium were different in the atrium, suggesting that the epicardial GP might be an independent intrinsic nervous system that mediates local reflexes. ${ }^{29}$

As documented in other studies of RF energy, ${ }^{12,30}$ there was difficulty in penetrating through adipose tissue. The low electrical and thermal conductivity properties of fat tissue are the most likely reason. The pen also might have tapered power delivery with its self-limiting feature after target tissue impedance reached $400 \Omega$ at a lower power. These findings might limit the use of this device in regions of epicardial fat.

\section{LIMITATIONS}

One limitation of this study was the use of an acute model. However, previous work from our laboratory has revealed that acute and chronic histologic results have been identical with RF technology. ${ }^{17,18}$ Second, these animals had normal atria. In patients with mitral valve disease, the atrial myocardium might be thickened and might yield different results, and the device might not perform as well. This will require clinical correlation. However, this study would suggest that 15 -second ablations are needed to ensure transmurality in atrial myocardium on both the beating and the arrested heart.

\section{CONCLUSION}

The bipolar pen effectively created transmural lesions on atrial tissue in a time-dependent manner on both beating and arrested hearts. Although the device did not reliably penetrate thick atrial tissue, it was capable of consistently creating transmural lesions near the AV annuli and coronary sinus musculature. This device might allow the surgeon to ablate tissue in regions not accessible to other technologies during AF surgery.

\section{References}

1. Damiano RJ Jr. Alternative energy sources for atrial ablation: judging the new technology. Ann Thorac Surg. 2003;75:329-30.

2. Doll N, Kiaii BB, Fabricius AM, Kornherr P, Krakor R, Gummert JF, et al. Intraoperative left atrial ablation for atrial fibrillation using a new argon cryocatheter: early clinical experience. Ann Thorac Surg. 2003;76:1711-5.

3. Knaut M, Spitzer SG, Karolyi L, Ebert HH, Richter P, Tugtekin SM, et al. Intraoperative microwave ablation for curative treatment of atrial fibrillation in open heart surgery: the MICRO-STAF and MICRO-PASS pilot trial. J Thorac Cardiovasc Surg. 1999;47(suppl):379-84.

4. Ninet J, Roques X, Seitelberger R, Deville C, Pomar JL, Robin J, et al. Surgical ablation of atrial fibrillation with off-pump, epicardial, high-intensity focused ultrasound: results of a multicenter trial. J Thorac Cardiovasc Surg. 2005; 130:803-9.

5. Gynor SL, Diodato MD, Prasad SM, Ishii Y, Schuessler RB, Bailey MS, et al. A prospective, single-center clinical trial of a modified Cox maze procedure with bipolar radiofrequency ablation. $J$ Thorac Cardiovasc Surg. 2004;128:535-42.

6. Damiano RJ Jr, Gaynor SL. Atrial fibrillation ablation during mitral valve surgery using the Atricure device. Operative Techniques Thorac Cardiovasc Surg. 2004; 9:24-33.

7. Bennussi S, Nasimbene S, Calori G, Denti P, Ziskind Z, Kassem S, et al. Surgical ablation of atrial fibrillation with a novel bipolar radiofrequency device. J Thorac Cardiovasc Surg. 2005; 130:491-7. 
8. Scherlag BJ, Nakagawa H, Jackman WM, Yamanashi WS, Patterson E, Po S, et al. Electrical stimulation to identify neural elements on the heart: their role in atrial fibrillation. J Interv Card Electrophysiol. 2005;13:37-42.

9. Thomas SP, Guy DJ, Boyd AC, Eipper VE, Ross DL, Chard RB. Comparison of epicardial and endocardial linear ablation using handheld probes. Ann Thorac Surg. 2003;24:481-6.

10. Bugge E, Nicholson LA, Thomas SP. Comparison of bipolar and unipolar radiofrequency ablation in an in vivo experimental model. Eur J Cardiothorac Surg. 2005;28:76-82

11. Gaynor SL, Byrd GD, Diodato MD, Ishii Y, Lee AM, Prasad SM, et al. Microwave ablation for atrial fibrillation: dose-response curves in the cardioplegia-arrested and beating heart. Ann Thorac Surg. 2006;81:72-7.

12. Doll N, Kornherr P, Aupperle H, Fabricius AM, Kiaii B, Ullmann C, et al. Epicardial treatment of atrial fibrillation using cryoablation in an acute off-pump sheep model. Thorac Cardiovasc Surg. 2003;51:267-73.

13. Aora RC, Waldmann M, Hopkins DA, Armour JA. Porcine intrinsic cardiac ganglia. Anat Rec A Discov Mol Cell Evol Biol. 2003;271:249-58.

14. Ho SY, Sanchez-Quintana D, Cabrera JA, Anderson RH. Anatomy of the left atrium: implication for radiofrequency ablation of atrial fibrillation. J Cardiovasc Electrophysiol. 1999;10:1525-33.

15. Sanchez-Quintana D, Anderson RH, Cabrera JA, Climent V, Martin R, Farre J, et al. The terminal crest: morphological features relevant to electrophysiology. Heart. 2002;88:406-11.

16. Cox JL, Schuessler RB, D'Agostino HJ, Stone CM, Chang BC, Cain ME, et al. The surgical treatment of atrial fibrillation. III. Development of a definitive surgical procedure. J Thorac Cardiovasc Surg. 1991;101:569-83.

17. Prasad SM, Maniar HS, Moustakidis P, Schuessler RB, Damiano RJ Jr. Epicardial ablation on the beating heart: progress towards an off-pump maze procedure. Heart Surg Forum. 2002;5:100-4.

18. Prasad SM, Maniar HS, Schuessler RB, Damiano RJ Jr. Chronic transmural atrial ablation by using bipolar radiofrequency energy on the beating heart. $J$ Thorac Cardiovasc Surg. 2002;124:708-13.

19. Akpinar B, Guden M, Sagbas E, Sanisoglu I, Caynak B, Bayramoglu Z. Roboticenhanced totally endoscopic mitral valve repair and ablative therapy. Ann Thorac Surg. 2006;81:1095-8.
20. Deneke T, Khargi K, Muller KM, Lemke B, Mugge A, Laczkovics A, et al Histopathology of intraoperatively induced linear radiofrequency ablation lesions in patients with chronic atrial fibrillation. Eur Heart J. 2005;26: 1797-803.

21. Sanchez-Quintana D, Cabrena JA, Climent V, Farre J, Mendonca MC, Ho SY Anatomic relations between the esophagus and left atrium and relevance for ablation of atrial fibrillation. Circulation. 2005;112:1400-5.

22. Becker AE. Left atrial isthmus: anatomic aspects relevant for linear catheter ablation procedures in humans. J Cardiovasc Electrophysiol. 2004;15:809-12.

23. Chauvin M, Shah DC, Haissaguerre M, Marcellin L, Brenchenmacher C. The anatomic basis of connections between the coronary sinus musculature and the left atrium in humans. Circulation. 2000;101:647-52.

24. Carlson J, Santos S, Platonov PG, Rasmussen OK, Johansson R, Olsson SB. Left atrial conduction along the coronary sinus during ectopic atrial tachycardia and atrial fibrillation: a study using correlation function analysis. J Cardiovasc Electrophysiol. 2003;14:148-53.

25. Pappone C, Santinelli V, Manguso F, Vicedomini G, Gugliotta F, Augello G, et al Pulmonary vein denervation enhances long-term benefit after circumferential ablation for paroxysmal atrial fibrillation. Circulation. 2004;109:327-34.

26. Scanavacca M, Pisani CF, Hachul D, Lara S, Hardy C, Darrieux F, et al. Selective atrial vagal denervation guided by evoked vagal reflex to treat patients with paroxysmal atrial fibrillation. Circulation. 2006;29:876-85.

27. Schuessler RB, Grayson TM, Bromberg BI, Cox JL, Boineau JP. Cholinergically mediated tachyarrhythmias induced by a single extrastimulus in the isolated canine right atrium. Circ Res. 1992;71:1254-67.

28. Liu L, Nattel S. Differing sympathetic and vagal effects on atrial fibrillation in dogs: role of refractoriness heterogeneity. Am J Physiol Heart Circ Physiol. 1997;273:H805-16.

29. Crick SJ, Anderson RH, Ho SY, Sheppard MN. Localization and quantitation of autonomic innervation in the porcine heart II: endocardium, myocardium and epicardium. J Anat. 1999;195(Part 3):359-73.

30. d'Avila A, Houghtaling BS, Gutierrez P, Vragovic O, Ruskin JN Josephson ME, et al. Catheter ablation of ventricular epicardial tissue: a comparison of standard and cooled-top radiofrequency energy. Circulation. 2004;109. 2363-9. 